\title{
Multimorbidity and Anxiety Symptoms among Adults Aged 50 Years and Over from Six Low- and Middle-Income Countries
}

\author{
Lee Smith ${ }^{1, *}$, Guillermo F. López Sánchez ${ }^{2}{ }^{\oplus}$, Jae Il Shin ${ }^{3}{ }^{\oplus}$, Pinar Soysal ${ }^{4}$, Nicola Veronese ${ }^{5}{ }^{\circledR}$, Karel Kostev ${ }^{6}$,

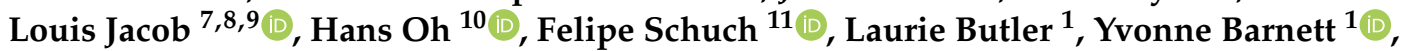 \\ Christopher Tejun Law ${ }^{12}$ and Ai Koyanagi ${ }^{7,8,13}$
}

check for updates

Citation: Smith, L.; López Sánchez, G.F.; Shin, J.I.; Soysal, P.; Veronese, N.; Kostev, K.; Jacob, L.; Oh, H.; Schuch, F.; Butler, L.; et al. Multimorbidity and Anxiety Symptoms among Adults Aged 50 Years and Over from Six Low- and Middle-Income Countries. J. Ageing Longev. 2021, 1, 36-47. https://doi.org/10.3390/ jal1010005

Academic Editor: Laurie Buys

Received: 14 September 2021

Accepted: 8 October 2021

Published: 14 October 2021

Publisher's Note: MDPI stays neutral with regard to jurisdictional claims in published maps and institutional affiliations.

Copyright: (c) 2021 by the authors. Licensee MDPI, Basel, Switzerland. This article is an open access article distributed under the terms and conditions of the Creative Commons Attribution (CC BY) license (https:/ / creativecommons.org/licenses/by/ $4.0 /)$.
1 Centre for Health, Performance, and Wellbeing, Anglia Ruskin University, Cambridge CB1 1PT, UK; laurie.butler@aru.ac.uk (L.B.); yvonne.barnett@aru.ac.uk (Y.B.)

2 Vision and Eye Research Institute, School of Medicine, Faculty of Health, Education, Medicine and Social Care, Anglia Ruskin University, Cambridge CB1 1PT, UK; guillermo.lopez-sanchez@aru.ac.uk

3 Department of Pediatrics, Yonsei University College of Medicine, Seoul 107-11, Korea; SHINJI@yuhs.ac

4 Department of Geriatric Medicine, Faculty of Medicine, Bezmialem Vakif University, Adnan Menderes Bulvarı (Vatan Street), Fatih, İstanbul 34093, Turkey; dr.pinarsoysal@hotmail.com

5 Geriatrics Section, Department of Medicine, University of Palermo, 90127 Palermo, Italy; ilmannato@gmail.com

6 Department of Epidemiology, IQVIA, 60549 Frankfurt am Main, Germany; Karel.Kostev@iqvia.com

7 Research and Development Unit, Parc Sanitari Sant Joan de Déu, Dr. Antoni Pujadas, 42, Sant Boi de Llobregat, 08830 Barcelona, Spain; louis.jacob.contacts@gmail.com (L.J.); koyanagi1117@gmail.com (A.K.)

8 Centro de Investigación Biomédica en Red de Salud Mental (CIBERSAM), 28029 Madrid, Spain

9 Faculty of Medicine, University of Versailles Saint-Quentin-en-Yvelines, 78000 Montigny-le-Bretonneux, France

10 Suzanne Dworak-Peck School of Social Work, University of Southern California, Los Angeles, CA 90015, USA; hansoh@gmail.com

11 Department of Sports Methods and Techniques, Federal University of Santa Maria, Santa Maria 97105-900, Brazil; felipe.schuch@ufsm.br

12 Barts and The London School of Medicine and Dentistry, Queen Mary University of London, London E1 4NS, UK; c.t.law@smd16.qmul.ac.uk

13 ICREA, Pg. Lluis Companys 23, 08010 Barcelona, Spain

* Correspondence: lee.smith@aru.ac.uk

\begin{abstract}
Currently, there are limited data on the association between multimorbidity (i.e., $\geq 2$ chronic conditions) and anxiety, especially among the older population in low- and middleincome countries (LMICs). Thus, the aim of the present study was to examine the association between multimorbidity and anxiety symptoms in a large sample of adults aged $\geq 50$ years from six LMICs (China, India, Ghana, Mexico, Russia, South Africa). Cross-sectional, nationally representative, community-based data from the Study on Global Ageing and Adult Health (SAGE) were analysed. A total of 11 chronic physical conditions were assessed. Anxiety symptoms referred to extreme/severe problems with worry or anxiety in the past 30 days. Multivariable logistic regression and meta-analyses were conducted. Data on 34,129 adults aged $\geq 50$ years were analysed (mean (SD) age 62.4 (16.0) years; $52.1 \%$ females). Compared with no chronic conditions, $2,3,4$, and $\geq 5$ chronic conditions were significantly associated with 1.47 (95\% CI $=1.08-1.98)$, $2.46(95 \% \mathrm{CI}=1.74-3.47), 3.04(95 \% \mathrm{CI}=2.15-4.30)$, and $4.70(95 \% \mathrm{CI}=2.99-7.38)$ times higher odds of anxiety symptoms, respectively. A country-wise analysis showed that multimorbidity was significantly associated with anxiety symptoms in all six countries $(\mathrm{OR}=1.78-12.39)$ with the overall estimate based on a meta-analysis being OR $=2.29(95 \% \mathrm{CI}=1.71-3.07)$. Multimorbidity was associated with higher odds of anxiety symptoms among older adults in LMICs. Future longitudinal studies are warranted to assess the temporal associations and mechanisms underlying this association.
\end{abstract}

Keywords: multimorbidity; anxiety; low- and middle-income countries; multicountry; epidemiology; older adults 


\section{Introduction}

Anxiety, an unpleasant mood characterised by thoughts of worry, is an adaptive response to perceived threats that can develop into a maladaptive anxiety disorder if it becomes severe and chronic [1]. Globally, 45.82 million (95\% uncertainty interval (UI): $37.14,55.62$ ) incident cases of anxiety disorders, 301.39 million (95\% UI: 252.63, 356.00) prevalent cases, and 28.68 (95\% UI: 19.86, 39.32) million disability-adjusted life years owing to anxiety were estimated in 2019 [2]. Importantly, anxiety disorders are the most common in older adults and have been found in $14-17 \%$ of this population [3-7]. The literature has identified that anxiety in old age is associated with an increased risk of multiple physical and mental health complications including a cognitive decline, impaired functioning, and premature mortality as well as a reduction in the quality of life [8]. The high prevalence of anxiety in older adults is of particular concern in low- and middle-income countries (LMICs) as this setting has a rapidly growing aging population [9]. Considering the high prevalence of anxiety in older adults, its detrimental impact on health, and the fact that the stigma of mental illness in LMICs may negatively influence help-seeking behaviours and thus lead to worse clinical outcomes for those with anxiety [10], it is of upmost importance to identify the key correlates or risk factors of anxiety to aid in the development of targeted interventions to prevent anxiety in older adults who reside in LMICs.

One potentially important but understudied correlate is that of multimorbidity, defined as the presence of two or more chronic conditions. Multimorbidity is plausibly associated with increased anxiety via factors such as the complexity of treating multiple conditions, treatment costs, symptoms per se, functional limitations, and polypharmacy [11-13]. However, to date and to the best of our knowledge, there are only two published studies specifically on the association between multimorbidity and anxiety. First, one cross-sectional study including 4219 older adults from the USA found that three or more medical conditions conferred a 2.30-fold increased risk of anxiety (95\% CI: 1.44-4.01) [14]. Second, one cross-sectional community-based study including data on 181,145 adults aged $\geq 18$ years from 40 LMICs and 2 high-income countries found that, compared with no chronic conditions, $2(\mathrm{OR}=2.63)$ to $5(\mathrm{OR}=5.49)$ chronic conditions were associated with significantly higher odds of anxiety symptoms [15].

A clear and important limitation of the existing literature on this topic is that, to date, there are no studies specifically on the older population of LMICs despite the fact that the prevalence of chronic conditions and anxiety are known to be particularly high among the older population; chronic conditions are increasing rapidly in this setting due to factors such as changes in lifestyles and urbanisation [16]. The results of the only study on the older population from the US are unlikely to be generalisable to people living in LMICs due to differences in the availability of health care for both mental health and physical health and different disease profiles. Furthermore, the only other study that included LMICs on the association between multimorbidity and anxiety symptoms included all adults aged $\geq 18$ years and the data were not exclusively from LMICs.

Given this background, the aim of the present study was to examine the association between multimorbidity and anxiety in nationally representative samples of 34,129 adults aged $\geq 50$ years from six LMICs (China, Ghana, India, Mexico, Russia, and South Africa).

\section{Methods}

Data from the Study on Global Ageing and Adult Health (SAGE) were analysed. These data are publicly available through http:/ / www.who.int/healthinfo/sage/en/ (accessed on 14 September 2021). This survey was undertaken in China, Ghana, India, Mexico, Russia, and South Africa between 2007 and 2010. These countries broadly represent different geographical locations and levels of socio-economic and demographic transition. Based on the World Bank classification at the time of the survey, Ghana was the only low-income country and China and India were lower middle-income countries although China became an upper middle-income country in 2010. The remaining countries were upper middle-income countries. 
Details of the survey methodology have been published elsewhere [17]. Briefly, to obtain nationally representative samples, a multistage clustered sampling design method was used. The sample consisted of adults aged $\geq 18$ years with oversampling of those aged $\geq 50$ years. Trained interviewers conducted face-to-face interviews using a standard questionnaire. Standard translation procedures were undertaken to ensure comparability between the countries. The survey response rates were: China 93\%; Ghana $81 \%$; India $68 \%$; Mexico 53\%; Russia 83\%; and South Africa 75\%. Sampling weights were constructed to adjust for non-responses and the population structure as reported by the United Nations Statistical Division. Ethical approval was obtained from the WHO Ethical Review Committee and local ethics research review boards. Written informed consent was obtained from all participants.

\subsection{Anxiety Symptoms (Dependent Variable)}

Anxiety symptoms were assessed by the question: 'Overall in the past 30 days, how much of a problem did you have with worry or anxiety?' with response options: none, mild, moderate, severe, and extreme. In accordance with previous SAGE publications, those who answered severe and extreme were considered to have anxiety symptoms [18,19].

\subsection{Chronic Physical Conditions and Physical Multimorbidity (Independent Variables)}

We included all 11 chronic physical conditions (angina, arthritis, asthma, chronic back pain, chronic lung disease, diabetes, edentulism, hearing problems, hypertension, stroke, visual impairment) for which data were available from the SAGE. Chronic back pain was defined as having had back pain every day during the last 30 days. Respondents who answered affirmatively to the question "Have you lost all of your natural teeth?" were considered to have edentulism. The participant was considered to have hearing problems if the interviewer observed this condition during the survey. Hypertension was defined as having at least one of the following: systolic blood pressure $\geq 140 \mathrm{mmHg}$; diastolic blood pressure $\geq 90 \mathrm{mmHg}$; or a self-reported diagnosis. Visual impairment was defined as having severe/extreme difficulty in seeing and recognising a person that the participant knew across the road [20]. Diabetes and stroke were solely based on a lifetime self-reported diagnosis. For other conditions, the participant was considered to have the condition in the presence of either one of the following: a self-reported diagnosis or a symptom-based diagnosis based on algorithms. We used these algorithms, which have been used in previous studies using the same dataset, to detect undiagnosed cases [21,22]. Specifically, the validated Rose questionnaire was used for angina [23] and other previously validated symptom-based algorithms were used for arthritis, asthma, and chronic lung disease [21]. Further details on the definition of chronic physical conditions can be found in Table A1 (Appendix A). The total number of chronic physical conditions was calculated and categorised as $0,1,2,3,4$, and $\geq 5$. Multimorbidity was defined as $\geq 2$ chronic physical conditions, in line with previously used definitions [22].

\subsection{Statistical Analysis}

The statistical analysis was performed with Stata 14.2 (Stata Corp LP, College Station, TX, USA). The analysis was restricted to those aged $\geq 50$ years. A multivariable logistic regression analysis was conducted to assess the association between the number of chronic conditions (exposures) and anxiety symptoms (outcome). Analyses using the overall sample and those stratified by age groups (i.e., 50-64 and $\geq 65$ years) and sex were conducted. A test for trend was also conducted by including the variable on the number of chronic conditions in the model as a continuous variable rather than a categorical variable. We also conducted analyses with the individual chronic conditions as the exposure variables. Furthermore, a country-wise analysis was also conducted to assess whether there was a between-country heterogeneity in the association between multimorbidity (i.e., $\geq 2$ chronic conditions) and anxiety symptoms. The Higgins's $\mathrm{I}^{2}$ statistic was also calculated, which represents the degree of heterogeneity that is not explained by sampling 
errors with values of $25 \%, 50 \%$, and $75 \%$ often being considered low, moderate, and high levels of heterogeneity, respectively [24]. A pooled estimate was obtained by combining the estimates for each country into a random effect meta-analysis. The regression analyses were adjusted for age, sex, education, wealth, depression, and country except for the sex-stratified and country-stratified analyses, which were not adjusted for sex and country, respectively. The analysis with the individual chronic conditions as the exposure variables included all 11 chronic conditions simultaneously in the model. An adjustment for the country was done by including dummy variables for each country in the model as in previous SAGE publications $[25,26]$. The sample weighting and the complex study design were considered in the analyses. The results from the regression analyses are presented as odds ratios (ORs) with $95 \%$ confidence intervals (CIs). The level of statistical significance was set at $p<0.05$.

\section{Results}

The final sample included 34,129 adults aged $\geq 50$ years (China $\mathrm{n}=13,175$; Ghana $\mathrm{n}=4305$; India $\mathrm{n}=6560$; Mexico $\mathrm{n}=2313$; Russia $\mathrm{n}=3938$; South Africa $\mathrm{n}=3838$ ). The sample characteristics are provided in Table 1. The mean (standard deviation; SD) age was $62.4(16.0)$ years and $52.1 \%$ were females. The overall prevalence of multimorbidity (i.e., $\geq 2$ chronic conditions) and anxiety symptoms were $45.5 \%$ and $8.1 \%$, respectively. The prevalence of anxiety symptoms, multimorbidity, and individual chronic conditions varied by country. For example, the ranges for anxiety and multimorbidity were $0.7 \%$ (China) to $17.8 \%$ (India) and $35.1 \%$ (Ghana) to $63.3 \%$ (Russia), respectively. The prevalence of anxiety symptoms increased sharply with an increasing number of chronic conditions (Figure 1). For example, in the overall sample, the prevalence of anxiety symptoms among those without chronic conditions was $5.4 \%$ but this increased to $22.6 \%$ among those with $\geq 5$ chronic conditions. In terms of individual chronic conditions, the results of the multivariable logistic regression analysis showed that visual impairment $(\mathrm{OR}=5.31)$, chronic lung disease $(\mathrm{OR}=2.15)$, diabetes $(\mathrm{OR}=1.70)$, stroke $(\mathrm{OR}=1.69)$, chronic back pain $(\mathrm{OR}=1.66)$, hearing problems $(\mathrm{OR}=1.54)$, and angina $(\mathrm{OR}=1.42)$ were all significantly associated with anxiety symptoms (Figure 2). Furthermore, compared with no chronic conditions, $2,3,4$, and $\geq 5$ chronic conditions were significantly associated with $1.47(95 \% \mathrm{CI}=1.08-1.98), 2.46(95 \% \mathrm{CI}=1.74-3.47), 3.04(95 \% \mathrm{CI}=2.15-4.30)$, and $4.70(95 \% \mathrm{CI}=2.99-7.38)$ times higher odds of anxiety symptoms, respectively (Table 2$)$. The results of the analyses stratified by age groups and sex were similar. Finally, a countrywise analysis showed that multimorbidity was significantly associated with anxiety symptoms in all six countries $(\mathrm{OR}=1.78-12.39)$ with the overall estimate based on a metaanalysis with the random effects being $\mathrm{OR}=2.29(95 \% \mathrm{CI}=1.71-3.07)$ (Figure 3). There was a moderate level of between-country heterogeneity $\left(\mathrm{I}^{2}=58.2 \%\right)$.

Table 1. Sample characteristics (overall and by country).

\begin{tabular}{ccccccccc}
\hline Characteristic & & Overall & China & Ghana & India & Mexico & Russia $\begin{array}{c}\text { South } \\
\text { Africa }\end{array}$ \\
\hline Anxiety symptoms & Yes & 8.1 & 0.7 & 7.1 & 17.8 & 5.2 & 4.4 & 9.4 \\
No. of chronic & 0 & 22.2 & 22.1 & 21.6 & 27.0 & 12.8 & 15.3 & 11.1 \\
conditions & 1 & 32.3 & 38.9 & 43.3 & 29.7 & 43.9 & 21.4 & 45.8 \\
& 2 & 22.4 & 22.7 & 24.3 & 21.4 & 23.9 & 23.6 & 21.6 \\
& 3 & 12.2 & 10.0 & 7.9 & 12.2 & 11.1 & 16.8 & 12.7 \\
& 4 & 6.4 & 4.2 & 2.0 & 5.7 & 5.0 & 12.2 & 5.7 \\
Age (years) & $\geq 5$ & 4.6 & 2.2 & 0.8 & 4.0 & 3.3 & 10.8 & 3.1 \\
Sex & Mean (SD) & $62.4(16.0)$ & $62.6(16.7)$ & $64.4(19.9)$ & $61.5(13.7)$ & $63.0(18.9)$ & $63.9(15.4)$ & $61.6(18.4)$ \\
Education & Female & 52.1 & 50.2 & 47.6 & 49.0 & 53.2 & 61.1 & 55.9 \\
& $\leq$ Primary & 57.4 & 63.0 & 75.3 & 76.1 & 79.6 & 7.5 & 71.4 \\
& Secondary & 35.2 & 32.5 & 21.1 & 18.8 & 12.3 & 74.2 & 22.8 \\
& Tertiary & 7.4 & 4.5 & 3.6 & 5.1 & 8.1 & 18.2 & 5.7 \\
\hline
\end{tabular}


Table 1. Cont.

\begin{tabular}{ccccccccc}
\hline Characteristic & & Overall & China & Ghana & India & Mexico & Russia & $\begin{array}{c}\text { South } \\
\text { Africa }\end{array}$ \\
\hline Depression & Yes & 6.0 & 1.1 & 7.2 & 12.9 & 10.8 & 3.5 & 3.0 \\
Angina & Yes & 17.6 & 9.4 & 12.8 & 17.0 & 6.7 & 37.3 & 8.9 \\
Arthritis & Yes & 29.5 & 26.7 & 26.2 & 27.9 & 14.5 & 38.2 & 30.6 \\
Asthma & Yes & 7.9 & 4.3 & 5.0 & 12.5 & 4.9 & 6.5 & 7.7 \\
Chronic back pain & Yes & 8.6 & 5.6 & 7.5 & 9.6 & 8.4 & 13.0 & 5.7 \\
Chronic lung disease & Yes & 15.8 & 11.3 & 3.7 & 17.2 & 13.2 & 24.4 & 7.4 \\
Diabetes & Yes & 6.8 & 6.6 & 3.8 & 6.9 & 17.6 & 7.0 & 9.2 \\
Edentulism & Yes & 12.9 & 9.1 & 3.0 & 15.1 & 21.7 & 18.1 & 8.5 \\
Hearing problems & Yes & 5.6 & 5.5 & 2.9 & 5.6 & 9.3 & 6.1 & 5.0 \\
Hypertension & Yes & 55.0 & 60.6 & 59.6 & 37.5 & 61.9 & 72.1 & 78.3 \\
Stroke & Yes & 3.0 & 3.0 & 2.8 & 2.0 & 4.3 & 4.8 & 4.0 \\
Visual impairment & Yes & 1.3 & 0.5 & 1.0 & 2.4 & 0.8 & 0.9 \\
\hline
\end{tabular}

SD: Standard deviation. Data are \% unless otherwise stated.

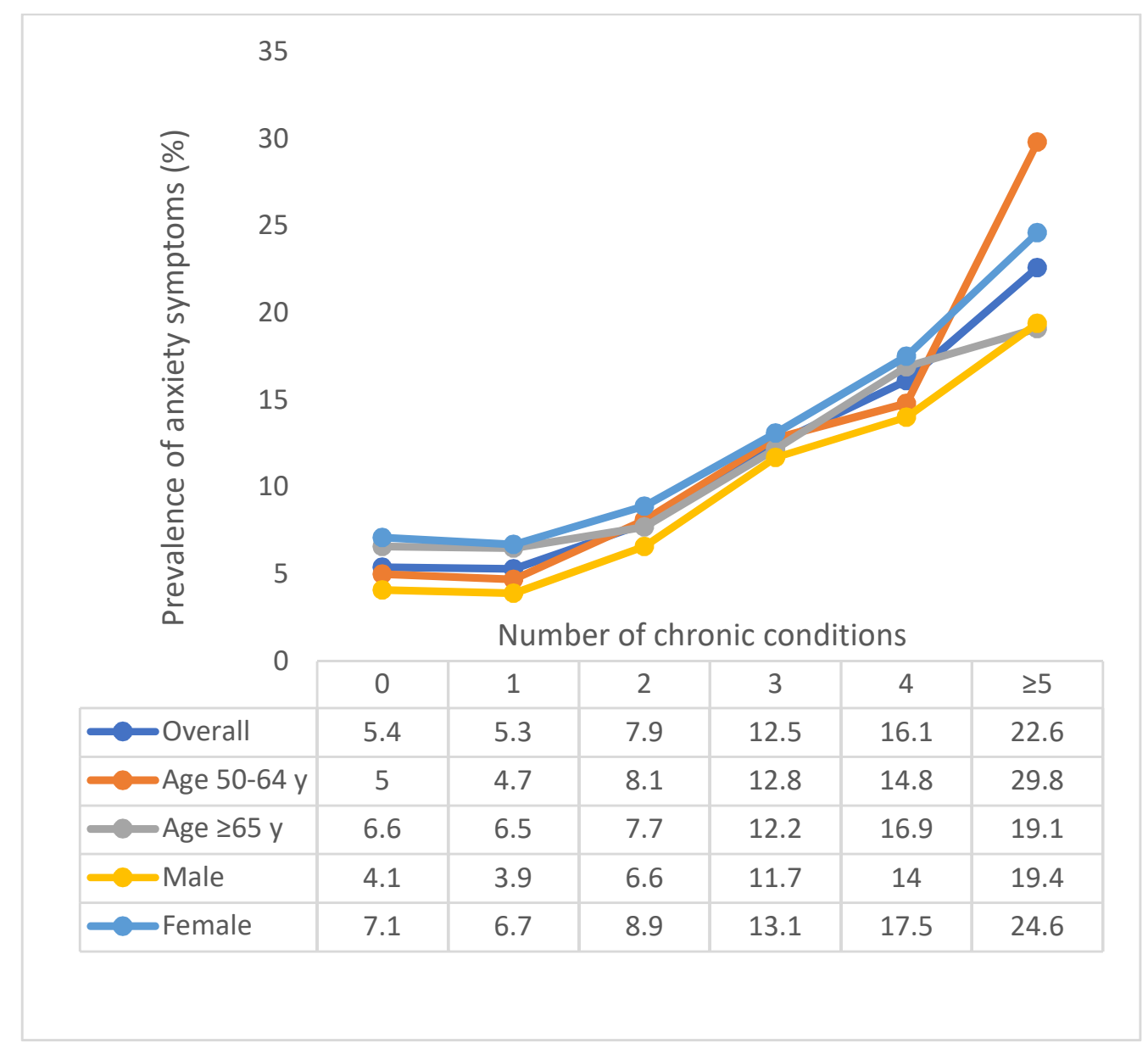

Figure 1. Prevalence of anxiety symptoms by the number of chronic conditions. 


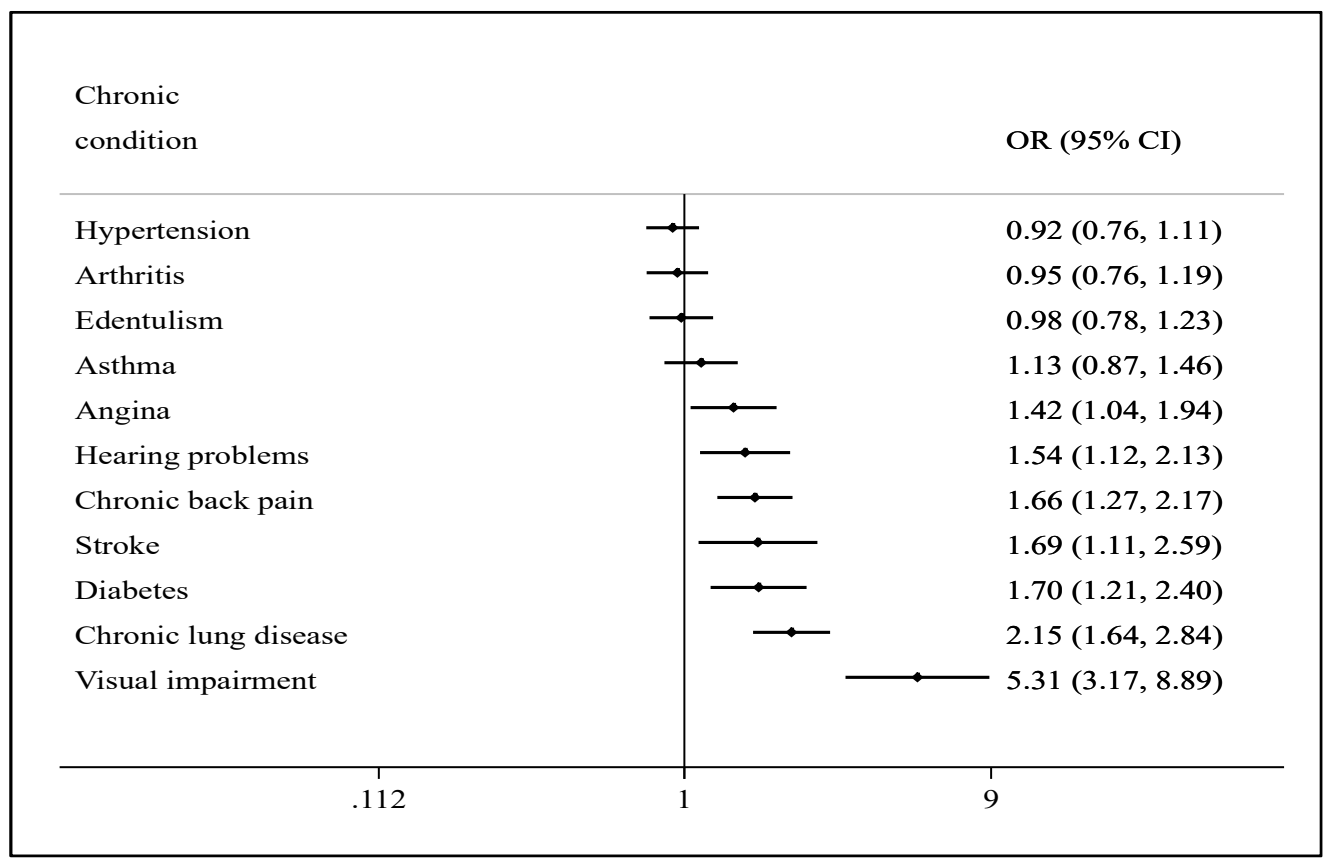

Figure 2. Association between individual chronic conditions and anxiety symptoms estimated by a multivariable logistic regression. OR: odds ratio; CI: confidence interval. The model is mutually adjusted for all individual chronic conditions and age, sex, education, wealth, depression, and country.

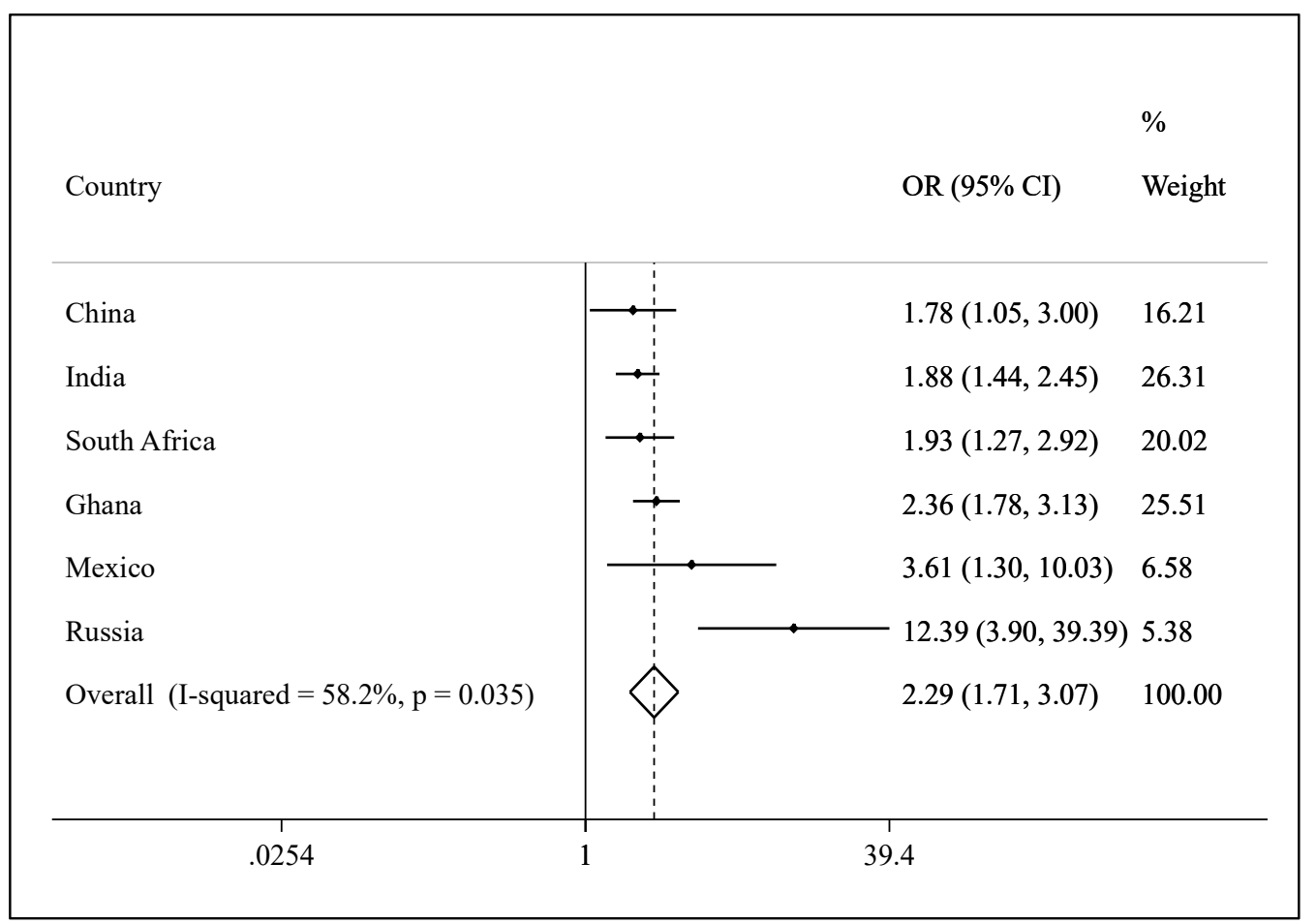

Figure 3. Country-wise association between multimorbidity (i.e., $\geq 2$ chronic conditions) and anxiety symptoms estimated by a multivariable logistic regression. OR: odds ratio; CI: confidence interval. The models are adjusted for age, sex, education, wealth, and depression. An overall estimate was obtained by a meta-analysis with random effects. 
Table 2. Association between the number of chronic conditions and the anxiety symptoms estimated by a multivariable logistic regression.

\begin{tabular}{|c|c|c|c|c|c|c|c|c|c|c|}
\hline \multirow{3}{*}{$\begin{array}{c}\text { Number of } \\
\text { Chronic } \\
\text { Conditions }\end{array}$} & \multirow{2}{*}{\multicolumn{2}{|c|}{ Overall }} & \multicolumn{4}{|c|}{ Age } & \multicolumn{4}{|c|}{ Sex } \\
\hline & & & \multicolumn{2}{|c|}{ 50-64 Years } & \multicolumn{2}{|c|}{$\geq 65$ Years } & \multicolumn{2}{|c|}{ Male } & \multicolumn{2}{|c|}{ Female } \\
\hline & OR & $95 \%$ CI & OR & $95 \%$ CI & OR & $95 \%$ CI & OR & $95 \%$ CI & OR & $95 \%$ CI \\
\hline 0 & 1.00 & & 1.00 & & 1.00 & & 1.00 & & 1.00 & \\
\hline 1 & 1.12 & $(0.87,1.44)$ & 1.05 & $(0.72,1.53)$ & 1.35 & $(0.82,2.23)$ & 1.17 & $(0.76,1.82)$ & 1.07 & $(0.78,1.48)$ \\
\hline 2 & $1.47 *$ & $(1.08,1.98)$ & $1.49 *$ & $(1.04,2.14)$ & 1.54 & $(0.97,2.46)$ & $1.81 *$ & $(1.10,2.99)$ & 1.28 & $(0.87,1.89)$ \\
\hline 3 & $2.46^{* * *}$ & $(1.74,3.47)$ & $2.45 * * *$ & $(1.57,3.83)$ & $2.72^{* * *}$ & $(1.50,4.92)$ & $3.65^{* * *}$ & $(2.14,6.22)$ & $1.93^{* *}$ & $(1.26,2.95)$ \\
\hline 4 & $3.04^{* * *}$ & $(2.15,4.30)$ & $2.32 * *$ & $(1.38,3.88)$ & $3.74^{* * *}$ & $(2.32,6.03)$ & $3.19^{* * *}$ & $(1.82,5.57)$ & $2.89^{* * *}$ & $(1.88,4.43)$ \\
\hline$\geq 5$ & $4.70^{* * *}$ & $(2.99,7.38)$ & $6.89^{* * *}$ & $\begin{array}{l}(3.48 \\
13.63)\end{array}$ & $4.07^{* * * *}$ & $(2.27,7.29)$ & $4.94^{* * *}$ & $(2.69,9.06)$ & $4.53^{* * *}$ & $(2.38,8.62)$ \\
\hline
\end{tabular}

OR: odds ratio; CI: confidence interval. Models are adjusted for age, sex, education, wealth, depression, and country with the exception of the sex-stratified analyses, which are not adjusted for sex. A significant test for the trend for all models $(p<0.05)$. ${ }^{*} p<0.05,{ }^{* *} p<0.01$, $* * * p<0.001$.

\section{Discussion \\ 4.1. Main Findings}

This is the first multi-LMIC study to examine the association between multimorbidity and anxiety in the older population. In terms of individual chronic conditions, it was found that visual impairment, chronic lung disease, diabetes, stroke, chronic back pain, hearing problems, and angina were all significantly associated with anxiety symptoms. Moreover, compared with no chronic conditions, 2, 3, 4, and $\geq 5$ chronic conditions were significantly associated with $1.47(95 \% \mathrm{CI}=1.08-1.98), 2.46(95 \% \mathrm{CI}=1.74-3.47)$, $3.04(95 \% \mathrm{CI}=2.15-4.30)$, and $4.70(95 \% \mathrm{CI}=2.99-7.38)$ times higher odds of anxiety symptoms, respectively, and similar associations were observed across sex and age groups. Multimorbidity (i.e., $\geq 2$ chronic conditions) was significantly associated with higher odds of anxiety symptoms across all six countries included in the study with a moderate level of between-country heterogeneity being observed.

\subsection{Interpretation of the Findings}

The finding that multimorbidity is associated with higher odds of anxiety (symptoms) is in line with previous studies on this topic conducted among older adults in the US and adults aged $\geq 18$ years in 2 high-income countries and 40 LMICs [14,15]. Our study shows for the first time that multimorbidity is strongly associated with anxiety symptoms in older adults from six LMICs, which represent nearly half of the global population [17], using nationally representative data.

We found that 7 out of the 11 chronic conditions assessed in our study were significantly associated with higher odds of anxiety symptoms. First, visual impairment and hearing problems likely increases anxiety owing to factors such as difficulties in interpersonal communication [27]. Second, chronic lung disease can result in anxiety via shortness of breath and difficulty in breathing deeply [28]. Angina may lead to increasing levels of anxiety for fear of imminent death during chest pain. Furthermore, anxiety in stroke patients is common [29,30] and may be a consequence of worry in relation to what might happen during physical exertion, sexual activity, and being alone at home as well as worry in relation to activities related to fear of having a headache, another stroke, or a fall [31]. Apart from these factors, others such as pain, sleep problems, functional limitations, and disability - which are common in many chronic diseases-may also increase the risk of anxiety [32-34]. For instance, functional limitations may increase the levels of anxiety via increased pain and a decreased sense of mastery [34].

It is possible to interpret the increasing odds of anxiety with an increasing number of chronic conditions to be attributable to the accumulative effect of the individual pathways mentioned above. For example, multimorbidity has been found to be associated with symptom burden, and such a burden is likely to have a direct consequence on increasing 
levels of anxiety. Indeed, symptom burden is defined as the subjective, quantifiable prevalence, frequency, and severity of symptoms, placing a physiologic burden on patients and producing multiple negative, physical, and emotional patient responses [35]. Apart from this, it is possible for multimorbidity to increase the risk of anxiety via other mechanisms. First, multimorbidity is associated with polypharmacy for the treatment of multiple conditions [36] and polypharmacy in turn may increase levels of anxiety through an increased risk of falls, fear of falling, and sleep problems [37,38]. Second, household expenditure in relation to the treatment of multiple chronic conditions is high in LMICs. Medicines are usually the largest component of costs and the use of originator brand medicines leads to higher than necessary expenses. Moreover, the costs associated with lost income-earning opportunities are also significant for many households [39]. This significant financial burden likely increases anxiety. Finally, the treatment of multimorbidity is complex often requiring attendance at multiple treatment centres and this complexity again likely increases anxiety.

Interestingly, in our study, there was a moderate level of between-country heterogeneity in the association between multimorbidity and anxiety. This was largely driven by the strong association observed in Russia because after excluding Russia from the meta-analysis, the $\mathrm{I}^{2}$ was reduced to $0.0 \%$. Although the reasons for the particularly strong association in Russia can only be speculated, it may be related to different disease profiles observed in this country compared with other countries. For example, the prevalence of angina was exceptionally high in this country and another study using the same dataset found that the co-occurrence of respiratory conditions such as chronic lung diseases and asthma are common in this country [22]. Furthermore, high levels of alcohol consumption in this country may increase the risk of chronic conditions and, at the same time, increase the risk of anxiety or worsen anxiety symptoms [40]. Clearly, more research is necessary to understand the particularly strong association observed in Russia.

\subsection{Clinical and Public Health Implications}

The findings from the present study suggest that it may be prudent to implement anxiety reduction interventions among those with multimorbidity. Addressing the issue of anxiety among those with multimorbidity is a unique challenge in LMICs where resources are often sparse and care may be fragmented. Thus, an important first step is raising awareness among health professionals of the importance of considering anxiety among those with multimorbidity. When designing public health initiatives to address anxiety among those with multimorbidity, it may be prudent to incorporate mind-body exercises into such interventions because these exercises have been found to be beneficial in the reduction of anxiety symptoms [41]. Moreover, mind-body exercises are also feasible among those with long-term chronic conditions [42]. To whatever extent possible, preventive interventions should address both mental and physical health together and integrated care systems should coordinate services to seamlessly assess and treat mental and physical health among older adults.

\subsection{Strengths and Limitations}

The large nationally representative sample of older adults from multiple LMICs is a clear strength of the present study. However, the findings must be interpreted in light of the study's limitations. First, the study was cross-sectional in nature and thus it is not known whether multimorbidity increases anxiety or whether anxiety increases the risk of multimorbidity. It is likely that the relationship is bidirectional. For example, anxiety may increase the risk of multimorbidity owing to elevated inflammation and immune dysregulation [43]. Most variables assessed in our study were based on self-reporting and thus reporting bias (recall, social desirability) is possible. Future studies should examine more objective measures of multimorbidity (e.g., insurance claims, medical records) and anxiety (clinical assessments). Furthermore, anxiety symptoms were assessed by a single question and this was not validated. However, the use of extreme categories (i.e., severe, 
extreme) likely improved specificity. Due to a lack of data, we were unable to control factors such as physical activity over the life course, which could have an effect on both the development of anxiety symptoms and physical multimorbidity.

Finally, our list of chronic diseases included a variety of diseases that are highly prevalent in LMICs but omitted a few diseases (such as cancer), which are known to be related to a higher risk of anxiety. There was also no information on the severity of the chronic conditions, from which more detailed analyses would have been possible.

\section{Conclusions}

Multimorbidity was significantly associated with higher odds of anxiety in older adults from LMICs. Future longitudinal studies in LMICs are warranted to assess the temporal associations and mechanisms underlying this association. Clinicians in LMICs should be aware of the high prevalence of anxiety symptoms in people with multimorbidity and treat them or address the underlying factors leading to anxiety when multimorbidity with anxiety symptoms is detected.

Author Contributions: Writing—original draft preparation, L.S. and A.K.; writing-review and editing, G.F.L.S., J.I.S., P.S., N.V., K.K., L.J., H.O., F.S., L.B., Y.B. and C.T.L. All authors have read and agreed to the published version of the manuscript.

Funding: This research received no external funding.

Institutional Review Board Statement: The study was conducted according to the guidelines of the Declaration of Helsinki and ethical approval was obtained from the WHO Ethical Review Committee and local ethics research review boards.

Informed Consent Statement: Written informed consent was obtained from all participants.

Data Availability Statement: Data supporting the findings of this study are available from the corresponding author upon reasonable request.

Acknowledgments: This paper uses data from the WHO's Study on Global Ageing and Adult Health (SAGE). SAGE is supported by the US National Institute on Aging through Interagency Agreements OGHA 04034785, YA1323-08-CN-0020, and Y1-AG-1005-01 and through research grants R01-AG034479 and R21-AG034263.

Conflicts of Interest: The authors declare no conflict of interest.

\section{Appendix A}

Table A1. Details on the diagnosis of chronic conditions.

\begin{tabular}{|c|c|c|}
\hline Condition & (a) Self-Reported Diagnosis & $\begin{array}{l}\text { (b) Symptom-Based Algorithm or Other Method } \\
\text { of Diagnosis a }\end{array}$ \\
\hline Angina & $\begin{array}{l}\text { Have you ever been diagnosed with angina or } \\
\text { angina pectoris (a heart disease)? }\end{array}$ & Rose questionnaire [23] \\
\hline Arthritis & $\begin{array}{l}\text { Have you ever been diagnosed with/told you } \\
\text { have arthritis (a disease of the joints, or by } \\
\text { other names rheumatism or osteoarthritis)? }\end{array}$ & $\begin{array}{l}\text { Affirmative answers to all four of the following: } \\
\text { 1. During the last } 12 \text { months, have you } \\
\text { experienced pain, aching, stiffness, or swelling in } \\
\text { or around the joints (e.g., in arms, hands, legs, or } \\
\text { feet), which were not related to an injury and } \\
\text { lasted for more than a month? } \\
\text { 2. During the last } 12 \text { months, have you } \\
\text { experienced stiffness in the joints in the morning } \\
\text { after getting up from bed or after a long rest of the } \\
\text { joints without movement? } \\
\text { 3. Did this stiffness last for less than } 30 \text { min? } \\
\text { 4. Did this stiffness go away after exercise or } \\
\text { movement in the joints? }\end{array}$ \\
\hline
\end{tabular}


Table A1. Cont.

\section{$\begin{array}{ll}\text { Condition } & \text { (a) Self-Reported Diagnosis }\end{array}$}

Asthma

Have you ever been diagnosed with asthma (an allergic respiratory disease)? (b) Symptom-Based Algorithm or Other Method of Diagnosis $^{\text {a }}$

1. During the last 12 months, have you experienced attacks of wheezing or whistling breathing? (Yes)

\section{AND}

2. "Yes" to at least one of the following (past 12 months):

(a) Have you experienced an attack of wheezing that came on after you stopped exercising or some other physical activity?

(b) Have you had a feeling of tightness in your chest?

(c) Have you woken up with a feeling of tightness in your chest in the morning or any other time?

(d) Have you had an attack of shortness of breath that came on without an obvious cause when you were not exercising or doing some physical activity?

1. During the last 12 months, have you experienced any shortness of breath at rest (while awake)? (Yes)

OR

$\begin{array}{ll}\text { Chronic lung disease } & \text { Have you ever been diagnosed with chronic } \\ \text { lung disease (emphysema, bronchitis, COPD)? }\end{array}$

2. "Yes" to both of the following (past 12 months):

(a) Have you experienced any coughing or wheezing for $10 \mathrm{~min}$ or more at a time?

(b) Have you experienced any coughing up of sputum or phlegm on most days of the month for at least 3 months?

Have you ever been diagnosed with diabetes (high blood sugar)? (Not including diabetes associated with a pregnancy)

NA

Diabetes

Have you ever been diagnosed with high blood pressure (hypertension)? one-minute interval with the use of a wrist blood
Blood pressure was measured three times with a pressure monitor (Medistar Wrist Blood Pressure Model S) and the mean value of the three measurements was calculated. Hypertension was defined as having at least one of the following: systolic blood pressure $\geq 140 \mathrm{mmHg}$ or diastolic blood pressure $\geq 90 \mathrm{mmHg}$.

NA

$\begin{array}{ll}\text { Stroke } & \begin{array}{l}\text { Have you ever been told by a health } \\ \text { professional that you have had a stroke? }\end{array}\end{array}$

For all chronic conditions, we assumed that the individual had the condition if they fulfilled at least one of the following: (a) an affirmative answer to a self-reported diagnosis or (b) a symptom-based algorithm or another method of diagnosis. ${ }^{\text {a }}$ These algorithms have been used in previous publications [21,22] and those of arthritis, asthma, and chronic lung disease have been validated [21,44].

\section{References}

1. Barlow, D.H. The experience of anxiety: Shadow of intelligence or specter of death. In Anxiety and Its Disorders: The Nature and Treatment of Anxiety and Panic, 2nd ed.; Guilford Press: New York, NY, USA, 2002; pp. 1-36.

2. Yang, X.; Fang, Y.; Chen, H.; Zhang, T.; Yin, X.; Man, J.; Yang, L.; Lu, M. Global, regional and national burden of anxiety disorders from 1990 to 2019: Results from the Global Burden of Disease Study 2019. Epidemiol. Psychiatr. Sci. 2021, 30, e36. [CrossRef]

3. Canuto, A.; Weber, K.; Baertschi, M.; Andreas, S.; Volkert, J.; Dehoust, M.C.; Sehner, S.; Suling, A.; Wegscheider, K.; Ausín, B. Anxiety disorders in old age: Psychiatric comorbidities, quality of life, and prevalence according to age, gender, and country. Am. J. Geriatr. Psychiatry 2018, 26, 174-185. [CrossRef]

4. Kirmizioglu, Y.; Doğan, O.; Kuğu, N.; Akyüz, G. Prevalence of anxiety disorders among elderly people. Int. J. Geriatr. Psychiatry 2009, 24, 1026-1033. [CrossRef] 
5. Miloyan, B.; Pachana, N.A. Clinical significance of worry and physical symptoms in late-life generalized anxiety disorder. Int. J. Geriatr. Psychiatry 2015, 30, 1186-1194. [CrossRef] [PubMed]

6. Norton, J.; Ancelin, M.L.; Stewart, R.; Berr, C.; Ritchie, K.; Carrière, I. Anxiety symptoms and disorder predict activity limitations in the elderly. J. Affect. Disord. 2012, 141, 276-285. [CrossRef] [PubMed]

7. Wolitzky-Taylor, K.B.; Castriotta, N.; Lenze, E.J.; Stanley, M.A.; Craske, M.G. Anxiety disorders in older adults: A comprehensive review. Depress. Anxiety 2010, 27, 190-211. [CrossRef] [PubMed]

8. Carriere, I.; Ryan, J.; Norton, J.; Scali, J.; Stewart, R.; Ritchie, K.; Ancelin, M.L. Anxiety and mortality risk in community-dwelling elderly people. Br. J. Psychiatry 2013, 203, 303-309. [CrossRef]

9. World Health Organization Global Health and Aging. Available online: https://www.who.int/ageing/publications/global_ health.pdf (accessed on 13 September 2021).

10. Mascayano, F.; Armijo, J.E.; Yang, L.H. Addressing stigma relating to mental illness in low-and middle-income countries. Front. Psychiatry 2015, 6, 38. [CrossRef]

11. Willadsen, T.G.; Siersma, V.; Nicolaisdottir, D.R.; Jarbol, D.; Guassora, A.D.; Reventlow, S.; Køster-Rasmussen, R. Symptom burden in multimorbidity: A population-based combined questionnaire and registry study from Denmark. BMJ Open 2021, 11 , e041877. [CrossRef]

12. Jindai, K.; Nielson, C.M.; Vorderstrasse, B.A.; Quiñones, A.R. Peer reviewed: Multimorbidity and functional limitations among adults 65 or older, NHANES 2005-2012. Prev. Chronic Dis. 2016, 13. [CrossRef]

13. NICE | The National Institute for Health and Care Excellence Multimorbidity and Polypharmacy. Available online: https://www. nice.org.uk/advice/ktt18/resources/multimorbidity-and-polypharmacy-pdf-58757959453381 (accessed on 13 September 2021).

14. Gould, C.E.; O'Hara, R.; Goldstein, M.K.; Beaudreau, S.A. Multimorbidity is associated with anxiety in older adults in the Health and Retirement Study. Int. J. Geriatr. Psychiatry 2016, 31, 1105-1115. [CrossRef] [PubMed]

15. Vancampfort, D.; Koyanagi, A.; Hallgren, M.; Probst, M.; Stubbs, B. The relationship between chronic physical conditions, multimorbidity and anxiety in the general population: A global perspective across 42 countries. Gen. Hosp. Psychiatry 2017, 45, 1-6. [CrossRef] [PubMed]

16. World Health Organization Chronic Diseases in Low and Middle Income Countries. Available online: https:/ /www.who.int/ chp/chronic_disease_report/media/Factsheet3.pdf (accessed on 2 September 2021).

17. Kowal, P.; Chatterji, S.; Naidoo, N.; Biritwum, R.; Fan, W.; Lopez Ridaura, R.; Maximova, T.; Arokiasamy, P.; Phaswana-Mafuya, N.; Williams, S. Data resource profile: The World Health Organization Study on global AGEing and adult health (SAGE). Int. J. Epidemiol. 2012, 41, 1639-1649. [CrossRef] [PubMed]

18. Vancampfort, D.; Stubbs, B.; Hallgren, M.; Veronese, N.; Mugisha, J.; Probst, M.; Koyanagi, A. Correlates of physical activity among community-dwelling individuals aged 65 years or older with anxiety in six low-and middle-income countries. Int. Psychogeriatr. 2018, 30, 705. [CrossRef]

19. Vancampfort, D.; Stubbs, B.; Herring, M.P.; Hallgren, M.; Koyanagi, A. Sedentary behavior and anxiety: Association and influential factors among 42,469 community-dwelling adults in six low-and middle-income countries. Gen. Hosp. Psychiatry 2018, 50, 26-32. [CrossRef]

20. Freeman, E.E.; Roy-Gagnon, M.; Samson, E.; Haddad, S.; Aubin, M.; Vela, C.; Zunzunegui, M.V. The global burden of visual difficulty in low, middle, and high income countries. PLoS ONE 2013, 8, e63315. [CrossRef] [PubMed]

21. Arokiasamy, P.; Kowal, P.; Capistrant, B.D.; Gildner, T.E.; Thiele, E.; Biritwum, R.B.; Yawson, A.E.; Mensah, G.; Maximova, T.; Wu, F. Chronic noncommunicable diseases in 6 low-and middle-income countries: Findings from wave 1 of the World Health Organization's study on global Ageing and adult health (SAGE). Am. J. Epidemiol. 2017, 185, 414-428. [CrossRef]

22. Garin, N.; Koyanagi, A.; Chatterji, S.; Tyrovolas, S.; Olaya, B.; Leonardi, M.; Lara, E.; Koskinen, S.; Tobiasz-Adamczyk, B.; Ayuso-Mateos, J.L. Global multimorbidity patterns: A cross-sectional, population-based, multi-country study. J. Gerontol. A Biol. Sci. Med. Sci. 2016, 71, 205-214. [CrossRef]

23. Rose, G.A. The diagnosis of ischaemic heart pain and intermittent claudication in field surveys. Bull. World Health Organ. 1962, 27,645 .

24. Higgins, J.P.; Thompson, S.G.; Deeks, J.J.; Altman, D.G. Measuring inconsistency in meta-analyses. BMJ 2003, 327, 557-560. [CrossRef]

25. Koyanagi, A.; Lara, E.; Stubbs, B.; Carvalho, A.F.; Oh, H.; Stickley, A.; Veronese, N.; Vancampfort, D. Chronic physical conditions, multimorbidity, and mild cognitive impairment in low-and middle-income countries. J. Am. Geriatr. Soc. 2018, 66, 721-727. [CrossRef]

26. Koyanagi, A.; Garin, N.; Olaya, B.; Ayuso-Mateos, J.L.; Chatterji, S.; Leonardi, M.; Koskinen, S.; Tobiasz-Adamczyk, B.; Haro, J.M. Chronic conditions and sleep problems among adults aged 50 years or over in nine countries: A multi-country study. PLoS ONE 2014, 9, e114742.

27. Binder, K.W.; Wrzesińska, M.A.; Kocur, J. Anxiety in persons with visual impairment. Psychiatr. Pol. 2020, 54, 279-288. [CrossRef] [PubMed]

28. American Lung Association Coping with COPD and Anxiety. Available online: https://www.lung.org/blog/coping-with-copdand-anxiety (accessed on 13 September 2021).

29. Burvill, P.W.; Johnson, G.A.; Jamrozik, K.D.; Anderson, C.S.; Stewart-Wynne, E.G.; Chakera, T. Anxiety disorders after stroke: Results from the Perth Community Stroke Study. Br. J. Psychiatry 1995, 166, 328-332. [CrossRef] [PubMed] 
30. Leppävuori, A.; Pohjasvaara, T.; Vataja, R.; Kaste, M.; Erkinjuntti, T. Generalized anxiety disorders three to four months after ischemic stroke. Cerebrovasc. Dis. 2003, 16, 257-264. [CrossRef] [PubMed]

31. Chun, H.Y.; Whiteley, W.N.; Dennis, M.S.; Mead, G.E.; Carson, A.J. Anxiety after stroke: The importance of subtyping. Stroke 2018, 49, 556-564. [CrossRef]

32. Anxiety and Depression Association of America Chronic Pain. Available online: https://adaa.org/understanding-anxiety/ related-illnesses / other-related-conditions / chronic-pain (accessed on 13 September 2021).

33. Taylor, D.J.; Lichstein, K.L.; Durrence, H.H.; Reidel, B.W.; Bush, A.J. Epidemiology of insomnia, depression, and anxiety. Sleep 2005, 28, 1457-1464. [CrossRef]

34. Backe, I.F.; Patil, G.G.; Nes, R.B.; Clench-Aas, J. The relationship between physical functional limitations, and psychological distress: Considering a possible mediating role of pain, social support and sense of mastery. SSM-Popul. Health 2018, 4, 153-163. [CrossRef]

35. Gapstur, R.L. Symptom burden: A concept analysis and implications for oncology nurses. Oncol. Nurs. Forum 2007, 34, 673-680. [CrossRef]

36. Cavalcanti, G.; Doring, M.; Portella, M.R.; Bortoluzzi, E.C.; Mascarelo, A.; Dellani, M.P. Multimorbidity associated with polypharmacy and negative self-perception of health. Rev. Bras. Geriatr. Gerontol. 2017, 20, 634-642. [CrossRef]

37. Ziere, G.; Dieleman, J.P.; Hofman, A.; Pols, H.A.; Van Der Cammen, T.; Stricker, B.C. Polypharmacy and falls in the middle age and elderly population. Br. J. Clin. Pharmacol. 2006, 61, 218-223. [CrossRef]

38. Sindi, S.; Pérez, L.M.; Vetrano, D.L.; Triolo, F.; Kåreholt, I.; Sjöberg, L.; Darin-Mattsson, A.; Kivipelto, M.; Inzitari, M.; Calderón-Larrañaga, A. Sleep disturbances and the speed of multimorbidity development in old age: Results from a longitudinal population-based study. BMC Med. 2020, 18, 382. [CrossRef]

39. Kankeu, H.T.; Saksena, P.; Xu, K.; Evans, D.B. The financial burden from non-communicable diseases in low-and middle-income countries: A literature review. Health Res. Policy Syst. 2013, 11, 31. [CrossRef] [PubMed]

40. Anker, J.J.; Kushner, M.G. Co-occurring alcohol use disorder and anxiety: Bridging psychiatric, psychological, and neurobiological perspectives. Alcohol. Res. Curr. Rev. 2019, 40. [CrossRef] [PubMed]

41. Nanthakumar, C. Yoga for anxiety and depression-A literature review. J. Ment. Health Train. Educ. Pract. 2020, 3, 157-169. [CrossRef]

42. Kubo, A.; Hung, Y.; Ritterman, J. Yoga for heart failure patients: A feasibility pilot study with a multiethnic population. Int. J. Yoga Therap. 2011, 21, 77-83. [CrossRef]

43. Vogelzangs, N.; Beekman, A.; De Jonge, P.; Penninx, B. Anxiety disorders and inflammation in a large adult cohort. Transl. Psychiatry 2013, 3, e249. [CrossRef]

44. Moussavi, S.; Chatterji, S.; Verdes, E.; Tandon, A.; Patel, V.; Ustun, B. Depression, chronic diseases, and decrements in health: Results from the World Health Surveys. Lancet 2007, 370, 851-858. [CrossRef] 